\title{
STABILIZATION OF SOFT SOIL WITH GRANULATED BLAST FURNACE SLAG AND FLY ASH
}

\author{
Laxmikant Yadu $^{1}$, R.K. Tripathi ${ }^{2}$ \\ ${ }^{1}$ Assistant Professor, Civil Engineering Department, NIT Raipur, Chhattisgarh, India, lkyadu.ce@nitrr.ac.in \\ ${ }^{2}$ Dean (Planning \& Development), NIT Raipur, Chhattisgarh, India, rajesh_tripathi64@yahoo.co.in
}

\begin{abstract}
Utilization of industrial waste materials in the improvement of problematic soils is a cost efficient and environmental friendly method. It helps in reducing disposal problems caused by the various industrial wastes. However, it is essential to understand the performance of these waste products prior to use. The present paper evaluated the potential of granulated blast furnace slag (GBS) with fly ash to stabilize a soft soil. Soft soil samples were collected from Tatibandh-Atari, rural road of Raipur, Chhattisgarh. This soil was classified as CI-MI as per Indian Standard Classification system (ISCS). Different amounts of GBS, i.e. 3, 6, and 9\% with different amount of fly ash i.e 3\%, 6\%, 9\% and 12\% were used to stabilize the soft soil. The performance of GBS with fly ash modified soils was evaluated using compaction and california bearing ratio (CBR) test. Based on these performance tests, optimum amount of GBS with fly ash was determined as 3\% fly ash + 6\% GBS. Reasonable improvement has been observed for unsoaked and soaked CBR value of soils with this optimum amount.
\end{abstract}

Index Terms: Granulated blast furnace slag, soft soil, fly ash, CBR, Compaction

\section{INTRODUCTION}

Soft soils show major volume changes due to change in the moisture content. This causes major damage to property constructed on it. These soils contain minerals such as montmorillonite that are capable of absorbing water. When they absorb water their volume increases. Although mechanical compaction, dewatering and earth reinforcement have been found to improve the strength of the soils, other methods like stabilization using admixtures are more advantageous. The different admixtures available are lime, cement, fly ash, blast furnace slag etc. At present cement stabilization nowadays is not preferable because of the increasing cost of cement and environmental concerns related to its production. Lime is also not suitable for soils which contains sulphates. Presence of sulfates can increase the swelling behavior of soil due to the formation of swelling minerals such as ettringite and thaumasite (Rajasekaran 2005).

With these considerations, the requirement of finding the other alternative materials is most promising one. This study focused on the use of the industrial waste materials like fly ash and GBS. Fly ash is a by-product from burning pulverized coal in electric power generating plants. GBS is obtained from blast furnace slag, a by-product from the manufacture of iron. Industrial waste materials have little or no production cost. Waste materials utilization is not only the promising solutions for disposal problem, but also saves construction cost.

The main objective of this paper is to investigate the potential of using industrial waste materials in the field of geotechnical engineering. Various researches have been done on fly ash and ground granulated blast furnace slag (GGBS) for the stabilization of expansive soils. Gupta and Seehra (1989) studied the effect of lime-GGBS on the strength of soil. They found that lime- GGBS soil stabilized mixes with and without addition of gypsum, or containing partial replacement of GGBS by fly ash produced high UCS and CBR in comparison to plain soil. They also concluded that partial replacement of GGBS with fly ash further increased the UCS. Akinmusuru (1991) studied the effect of mixing of GGBS on the consistency, compaction characteristics and strength of lateritic soil. He observed a decrease in both the liquid and plastic limits and an increase in plasticity index with increasing GGBS addition. Further, he observed that the compaction, cohesion and CBR increased with increasing the GGBS content up to $10 \%$ and then subsequently decreased. The angle of internal friction decreased with increasing GGBS percentage.

Cokca (2001) has studied the effect of fly ash on the properties of expansive soil prepared in the laboratory using kaolinite and bentonite. He has recommended that fly ashes can be used as effective stabilizing agents for improvement of expansive soils. Pandian (2002) conducted laboratory CBR tests on the stabilized fly ash-soil mixtures and found that fly is an effective admixture for improving the soil quality. Sridharan (1997) has studied the effect of fly ash on the unconfined compressive strength of black cotton soils found in India which is typically an expansive soil. Yadu et. al. (2011 a, b) studied the potential of rice husk ash (RHA) for the 
stabilization of black cotton soil. They concluded that RHA is a cost effective locally available material for pavement construction and RHA has significant potential to improve the physical, swelling and strength properties of black cotton soil. Yadu et.al. (2011c) compared the potential of RHA and fly ash to stabilize the black cotton soil and determined the optimal amount of each additive. Sharma and Shivapullaiah (2011) studied the compaction behavior and effect of unconfined strength of soil stabilized with fly ash and GGBS. They found that the addition of GGBS with and without fly ash and lime has significant influence on the geotechnical characteristics of the soil.

Above studies, motivated the authors to investigate the potential of industrial wastes i.e. fly ash and non grounded granulated blast furnace slag (GBS) to stabilize the soft soil.

\section{MATERIAL USED AND METHODOLOGY}

\subsection{Soft Soil}

The soft soil was collected from Tatibandh-Atari rural road district Raipur, Chhattisgarh, India at a depth of 0.4 meter for this study.

\subsection{Granulated blast furnace slag}

Granulated blast furnace slag (GBS) was obtained from Bhilai steel plant district Durg, Chhattisgarh, India.

\subsection{Fly Ash}

The FA has been collected from nearby thermal power station at Urla district Raipur, Chhattisgrh, India.

Properties of soft soil, GBS and fly ash are determined as per the Bureau of Indian Standard (BIS). Properties of soft soil are tabulated in Table 1. The raw soil was identified as inorganic fine grained expansive (Free Swell Index value 83\%) soil with blackish gray in color. Table 2 shows the properties of GBS and fly ash. Fig. 1 and 2 shows the dry soil sample and fly ash respectively used in this study.

\subsection{Methodology}

The soil collected from the site was pulverized with wooden mallet to break lumps and then air-dried. Processing of fly ash was done on the similar line as that of raw soil. Oven dried granulated blast furnace slag (GBS) was used for mixing with fly ash-soil mixture. A number of soil-fly ash-GBS combinations were used to determine the compaction and strength properties of blended mixes in accordance with BIS. Table 3 shows the combination of the soil-fly ash-GBS mixes. Total twelve trial combinations were formed, and compaction and strength properties of blended mixes were evaluated in the laboratory.
Table 1: Properties of soft soil

\begin{tabular}{|l|c|c|}
\hline \multicolumn{1}{|c|}{ Properties } & GBS & Fly Ash \\
\hline Liquid limit & - & $78 \%$ \\
\hline Plastic limit & $\mathrm{NP}$ & $\mathrm{NP}$ \\
\hline Specific gravity & 2.89 & 2.09 \\
\hline pH value dry density & 8.4 & - \\
\hline Maximum content & $9.3 \%$ & 13.2 \\
\hline Optimum moisture & $4.1 \%$ & - \\
\hline CBR value (soaked) & $11.14 \%$ & 19.29 \\
\hline CBR value (unsoaked) &
\end{tabular}

Table2. Properties of GBS and Fly Ash

\begin{tabular}{|l|c|}
\hline \multicolumn{1}{|c|}{ Soil Properties } & Description \\
\hline Field Moisture Content & $18.5 \%$ \\
\hline Liquid limit & $46 \%$ \\
\hline Plastic limit & $29 \%$ \\
\hline Plasticity index & $17 \%$ \\
\hline Maximum dry density & $17.6 \mathrm{kN} / \mathrm{m}^{3}$ \\
\hline Optimum moisture content & $11 \%$ \\
\hline CBR value (soaked) & $2.05 \%$ \\
\hline CBR value (unsoaked) & $8.14 \%$ \\
\hline Free swelling index & $83 \%$ \\
\hline Swelling pressure & $41.8 \mathrm{kN} / \mathrm{m}^{2}$ \\
\hline Specific gravity & 2.56 \\
\hline pH value & 7.62 \\
\hline Indian Standard Soil Classification & CI-MI \\
\hline AASTHO Classification & A-7-5 (4) \\
\hline
\end{tabular}

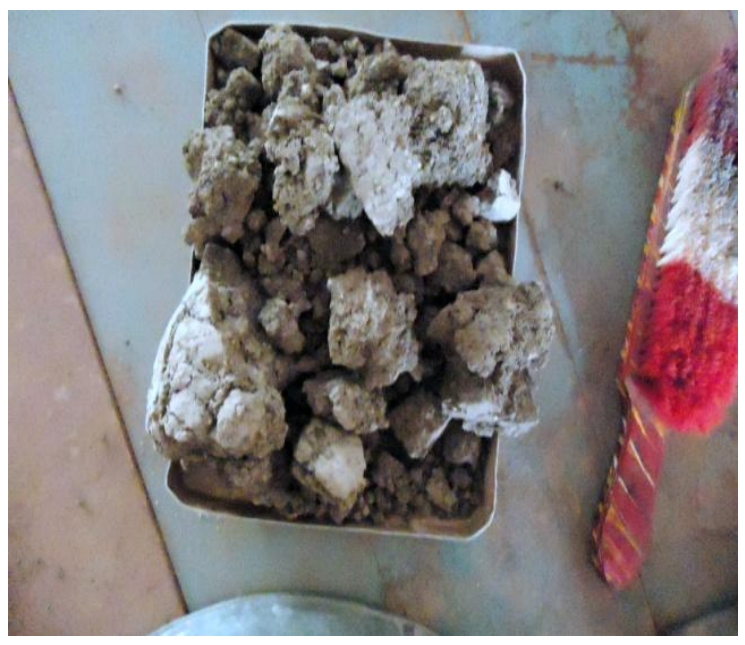

Fig -1: Dry Soil Sample 


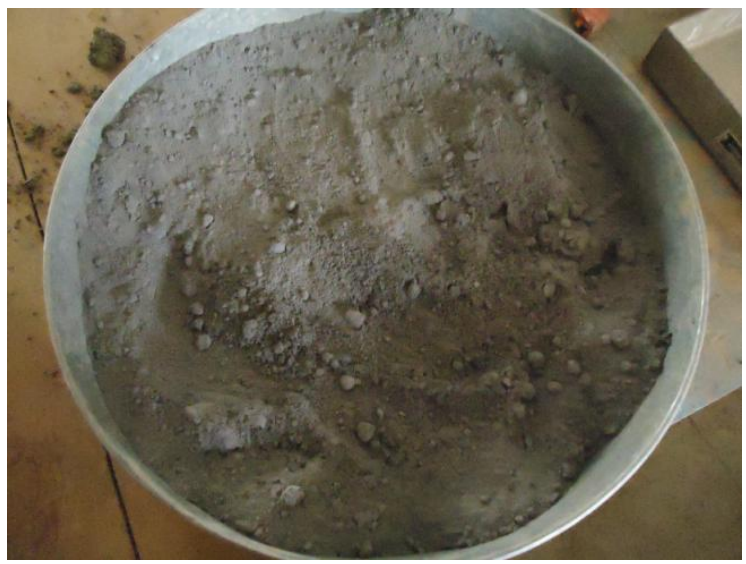

Fig -2: Fly Ash

Table 3: Combinations of additive with soil

\begin{tabular}{|c|c|c|c|}
\hline Sl. N. & Soil (\%) & Fly ash (\%) & GBS $(\%)$ \\
\hline 1 & 96 & 3 & 3 \\
\hline 2 & 91 & 3 & 6 \\
\hline 3 & 88 & 3 & 9 \\
\hline 4 & 91 & 6 & 3 \\
\hline 5 & 88 & 6 & 6 \\
\hline 6 & 85 & 6 & 9 \\
\hline 7 & 88 & 9 & 3 \\
\hline 8 & 85 & 9 & 6 \\
\hline 9 & 82 & 9 & 9 \\
\hline 10 & 85 & 12 & 3 \\
\hline 11 & 83 & 12 & 6 \\
\hline 12 & 79 & 12 & 9 \\
\hline
\end{tabular}

\section{RESULT AND DISCUSSION}

\subsection{Effect of compaction properties}

Compaction properties i.e. maximum dry density (MDD) and optimum moisture content (OMC) were determined in the laboratory of all trial mixture in accordance with IS: 2720 (Part 8) - 1983. Variations of MDD and OMC of the mixes are shown in figs 3 and 4 respectively. From the figs 4 and 5, it is conferred that OMC increased and MDD decreased with increasing percentage of fly ash - GBS mixtures which is consistent with observations reported by Akinmusuru (1991). The decrease in the MDD can be attributed to the replacement of soil by the fly ash in the mixture which has relatively lower specific gravity (2.09) compared to that of the raw soil which is 2.56 . The MDD increases by increasing the content of GBS in fly ash-GBS mixtures. This increase in MDD may be explained by considering the GBS as filler with higher specific gravity in the soil-fly ash voids. The increase in OMC due to addition of fly ash may be caused by the absorption of water by fly ash. This implies more water is needed in order to compact the soil with fly ash mixtures.

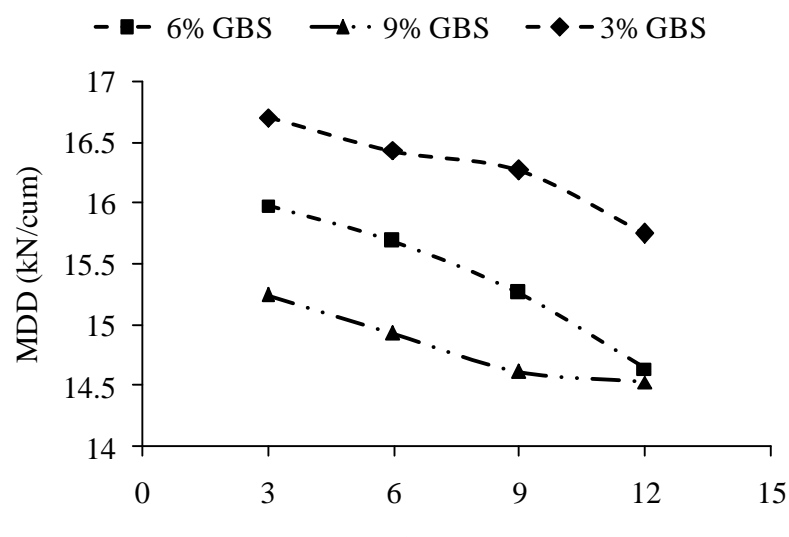

Fly Ash (\%)

Fig -3: Variation of MDD with fly ash and GBS mix

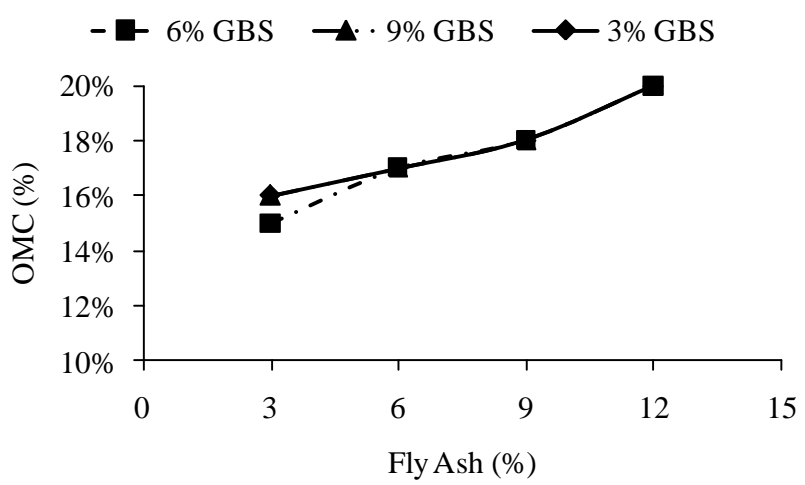

Fig -4: Variation of OMC with fly ash and GBS mix

\subsection{Effect on CBR}

CBR test is one of the common tests for evaluating the strength of stabilized soils. The soaked CBR tests were conducted on samples compacted at OMC, and soaked for 96 hours in accordance with IS: 2720 (Part 16) - 1987. The variation in soaked and unsoaked CBR value with addition of fly ash-GBS mixtures is shown in fig 6 and 7 respectively, which is consistent with Sharma and Shivapullaiah (2011) and Akinmusuru (1991). Both the soaked and unsoaked CBR of fly ash-GBS mixture increases with the increase in the GBS content. Similar trend have been observed for all other mixtures except fly ash-GBS mixtures with $3 \%$ GBS content. With addition of fly ash, CBR value increases and then became constant for $3 \%$ GBS content fly ash-GBS mixtures. From the fig 5 and 6 it is conferred that soaked CBR value of raw soil increased from $2.05 \%$ to its maximum value of 8.29 $\%$ with addition of $3 \%$ fly ash and $6 \%$ GBS. The same trend has been obtained for the unsoaked CBR also. The initial 
increase in the CBR is expected because of gradual formation of cementitious compounds between the fly ash-GBS and $\mathrm{CaOH}$ present in the soil. The gradual decrease in the CBR is due to excess fly ash-GBS that was not mobilized in the reaction, which consequently occupies spaces within the sample and therefore reduces bond in the soil and fly ash-GBS mixtures.

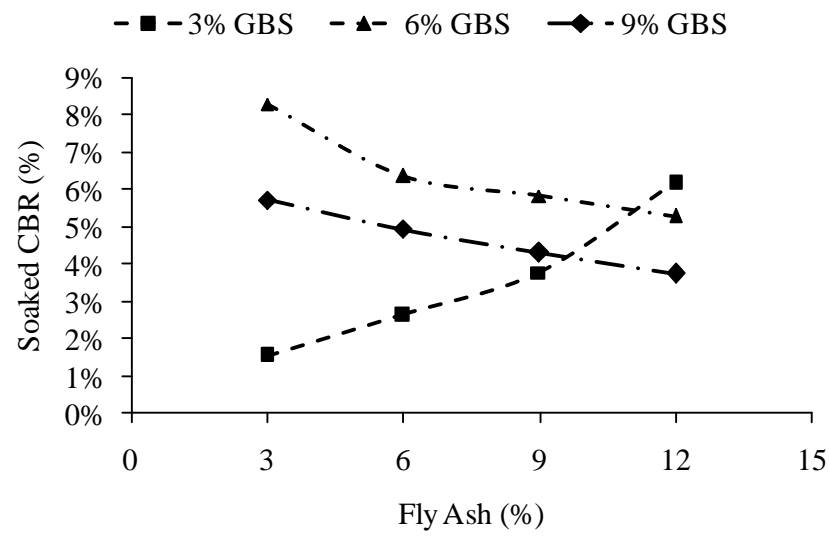

Fig -5: Variation of soaked CBR with fly ash and GBS mix

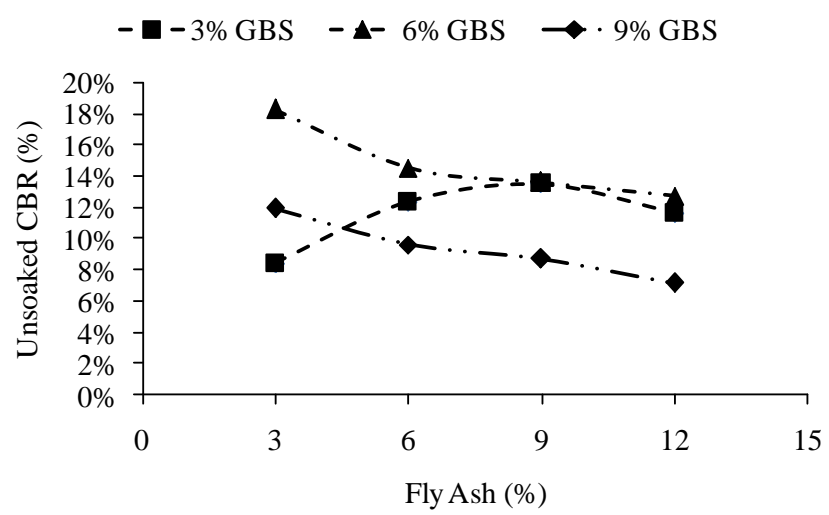

Fig -6: Variation of unsoaked CBR with fly ash and GBS mix

\section{CONCLUSIONS}

Based on the findings of the present investigation, the following conclusions can be drawn:

1. OMC increased and MDD decreased with the addition of fly ash-GBS mixture to the soft soil, Moreover MDD increased with increase in GBS content in fly ash-GBS mixtures. This is due to predominant effects of reduced clay content and increased frictional resistance respectively.

2. Both the soaked and unsoaked CBR of fly ash-GBS mixture increases with the increase in the GBS content.
3. $3 \%$ fly ash $+6 \%$ GBS mixture is determined as optimum percentage as an additive for the soft soil.

Based on the results of this research, it appears that soft soil can be effectively stabilised with the addition of fly ash-GBS mixtures. Fly ash- GBS mixtures are suitable for use in rural roads, embankments and it be used as provide fill materials of comparable strength.

\section{ACKNOWLEDGEMENTS}

The authors gratefully acknowledge Chhattisgarh Council of Science and Technology for providing the fund to carry out this research work. The authors also acknowledge the contribution of the final year undergraduate students and technician for their help in conducting laboratory tests

\section{REFERENCES:}

[1] Akinmusuru, J. O (1991), "Potential Beneficial Uses of Steel Slag Wastes for Civil Engineering Purposes", Resources Conservation and Recycling, Vol. 5, PT1, pp. 73-80.

[2] Çokca, E. (2001) Use of class C fly ashes for the Stabilization - of an expansive soil, Journal of Geotechnical and Geoenvironmental Engineering, 127, 568-573.

[3] Pandian, N.S. and K.C. Krishna. (2002). "The Pozzolanic Effect of Fly Ash on the CBR Behaviour of Black Cotton Soil". J.of Testing and Evaluation, ASTM, 31(6), 479-485.

[4] Rajasekaran,G.(2005),"Sulphate attack and ettringite formation in the lime and cement stabilized marine clays". Journal of Ocean Engineering, 32, 1133-1159.

[5] Sridharan, A., Prashanth, J.P., and Sivapullaiah, P.V. (1997). "Effect of fly ash on the unconfined strength of black cotton soil". Ground Improvement, 1, 169-175.

[6] Sharma A.K., and Shivapulliah P.V. (2011). "Soil Stabilisation with Waste Materials Based Binder". Proceedings of Indian Geotechnical Conference December 15-17,2011, Kochi.

[7] Sharma A.K. and Sivapullaiah P.V. "Improvement of Strength of Expansive Soil with Waste Granulated Blast Furnace Slag" Geo Congress 2012.

[8] S. Gupta, and S. S. Seehra, (1989), "Studies on LimeGranulated Blast Furnace Slag as an Alternative Binder to Cement", Highways Research Board, Bulletin, No. 38, pp. 81-97.

[9] Yadu, L.K., Tripathi, R.K., and Singh, D.V. (2011a). "Laboratory Performance Evaluation of Stabilized Black Cotton Soil with Rice Husk Ash," Journal of Chhattisgarh Swami Vivekanand Technical University Bhilai, Volume 4, No. 1, pp 50-55.

[10] Yadu, L.K., Singh, D.V., and Tripathi, R.K. (2011b). "Strength Characteristics of Rice Husk Ash Stabilized Black Cotton Soil," Proceedings of International Conference on Advances in Materials and Techniques 
for Infrastructure Development (AMTID 2011), September 28-30,Paper No. T022.

[11] Yadu, L.K., Tripathi, R.K., and Singh, D.V. (2011c). "Comparison of Fly Ash and Rice Husk Ash Stabilized Black Cotton Soil," International Journal of Earth Sciences and Engineering, Volume 04, No. 06 SPL, pp $42-45$.

\section{BIOGRAPHIES:}

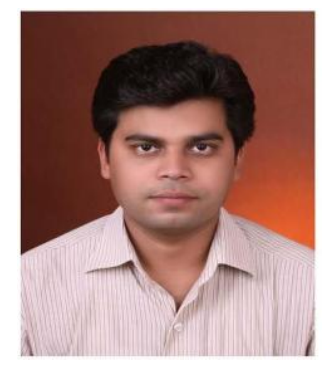

Laxmikant Yadu is Assistant Professor in Civil Engineering Department at National Institute of Technology Raipur. His area of specialization is Geotechnical Engineering. he has published more than 10 research papers in various reputed International and National Journals and Conferences.

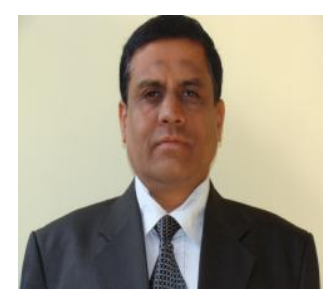

Rajesh Kumar Tripathi is Dean (Planning \& Development) and Associate Professor in Civil Engineering Department at National Institute of Technology Raipur. His area of specialization is Structural Engineering. He has published more than 40 research papers in various reputed International and National Journals and Conferences. 